\title{
Correlation of Tumor Necrosis Factor- $\alpha$ Expression with Pain Level in Degenerative Lumbar Canal Stenosis Patients
}

\author{
Yudha Mathan Sakti ${ }^{1}$, Rahadyan Magetsari ${ }^{1}$, David Yosua Parulian Hutahaean ${ }^{1}$, Galih Prasetya Sakadewa ${ }^{1}$, \\ Paramita Dyah Lasmana ${ }^{1}$, Nicolaas C. Budhiparama ${ }^{2}$, Ery Kus Dwianingsih ${ }^{3 *} \mathbb{D}$ \\ ${ }^{1}$ Department of Orthopaedics and Traumatology, Faculty of Medicine, Public Health and Nursing, Universitas Gadjah Mada, \\ Yogyakarta, Indonesia; ${ }^{2}$ Nicolaas Institute of Constructive Orthopaedic Research and Education Foundation for Arthroplasty \\ and Sports Medicine, Medistra Hospital, Jakarta, Indonesia; ${ }^{3}$ Department of Pathological Anatomy, Faculty of Medicine, Public \\ Health and Nursing, Universitas Gadjah Mada, Yogyakarta, Indonesia;
}

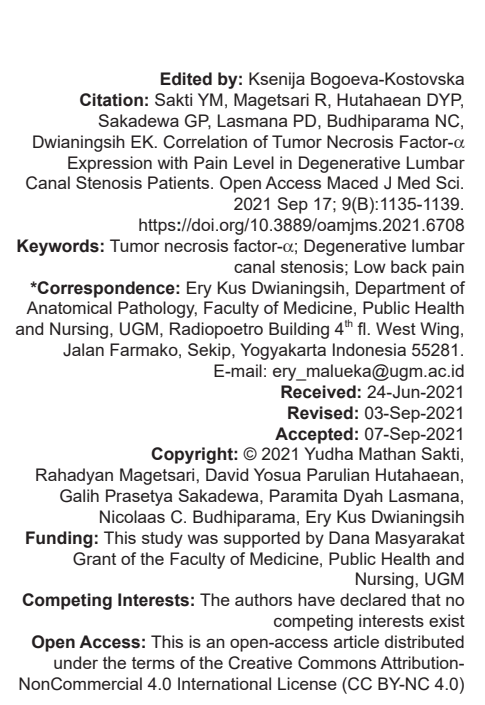

\section{Introduction}

A degenerative process that occurs in the spine can cause the narrowing of the spinal canal, especially in the lower spine, and induce inflammation in the specific structures of the spine. Inflammatory processes, exacerbated by cytokines, including tumor necrosis factor- $\alpha$ (TNF- $\alpha$ ) and interleukin-1 $\beta$ (IL-1 $\beta$ ), are thought to be the key substances during disc degeneration [1], [2] TNF- $\alpha$ and IL-1 $\beta$ play an important role in the natural resolution of disc herniation. TNF- $\alpha$ is required to induce metalloproteinase matrix-3 in the herniated tissue, which acts as a chemoattractant for macrophages [3]. Other structures, such as annulus fibrosus, facet joint, paraspinal muscle, and flavum ligament on the posterior of the spinal canal, might contribute to the degenerative spinal stenosis. There has not been a comprehensive study explaining how inflammation in specific structures of the spine plays a role in the degenerative process of the spine.

This study aimed to evaluate the expression of the TNF- $\alpha$ in specific structures and its correlation to the level of pain, type of pain, and functional pre-operative score.

\section{Methods}

\section{Subjects and study design}

This research has been approved by the IRB of the authors' affiliated institution. Informed written consent was obtained from each eligible patient. Patients diagnosed with degenerative lumbar canal stenosis and planned for surgical treatment in our hospital between June 2017 to July 2018 were 
included in this study. Patients with a history of fracture, neoplasm, and/or infection of the spine were excluded. Initial diagnosis of lumbar degenerative disease was made based on clinical manifestations, medical history, and physical examinations. The diagnosis was confirmed using imaging examination and lower nucleus signal on T2-weighted with magnetic resonance imaging. Tissue samples of nucleus pulposus, annulus fibrosus, and facet joint were collected during the surgery.

\section{Semi-quantitative RT-PCR}

Ribonucleic acid (RNA) was extracted using Rneasy Mini Kit, Cat \#74104, Qiagen (USA) according to the manufacturer's protocol. Complementary deoxyribonucleic acid (cDNA) was synthesized from total RNA samples using High-Capacity RNA to cDNA Kit (LOT 00788700) from Applied Biosystem (Thermo Fisher Scientific). The amplification was performed using Platinum DNA polymerase High Fidelity, Invitrogen (Thermo Fisher Scientific) using the following conditions: 1 cycle of $50^{\circ} \mathrm{C}$ for 2 min and $95^{\circ} \mathrm{C}$ for $5 \mathrm{~min}$; followed by 40 cycles of $95^{\circ} \mathrm{C}$ for $15 \mathrm{~s}$ and $60^{\circ} \mathrm{C}$ for $1 \mathrm{~min}$. The primer sequences used in this study are TNF $\alpha-F$ CAATCCCTTTATTACCC; TNF $\alpha$-R GTCTTCTCAAGTCCTGC (expected size 293bp), and glyceraldehyde 3-phosphate dehydrogenase (GAPDH)-F GCACCGTCAAGGCTGAGAAC; GAPDH-R TGGTGAAGACGCCAGGGA (expected size 138bp). Amplification products were run in electrophoresis gel (2\%) and visualized under ultraviolet light. The bands length was marked with ExactMark 100bp DNA Ladder ( $1^{\text {st }}$ Base, Axil Scientific Pte Ltd). Those bands were then measured qualitatively using Image-G software with GAPDH as the internal control. TNF- $\alpha$ expression was semi-quantitatively analyzed using image- $G$ by comparing $\mathrm{TNF}-\alpha$ expression in experimental and control tissues.

\section{Pain evaluation}

Preoperative axial and radicular pain levels were measured using the Visual Analog Scale (VAS) score. The patients were also interviewed preoperatively using Oswestry Disability Index (ODI) to measure the clinical outcomes. The VAS and ODI score were taken 1 day prior to surgery to closely relate patients' condition and tissue evaluation.

\section{Statistical analysis}

The results were then statistically analyzed using SPSS software, version 23 (SPSS, Inc., Chicago, IL, USA). Homogeneity was measured using ShapiroWilk tests. Correlation between two variables was analyzed with Spearman correlation analysis. Oneway analysis of variants was used to compare multiple groups and least significant difference t-test was used to compare two groups, with $p<0.05$ considered as a statistically significant difference.

\section{Results}

Ten subjects were enrolled in this study with 6 males and 4 females and the average age of 50 years. Agarose gel electrophoresis demonstrated that the sizes of the semiquantitative Polymerase Chain Reaction amplified products of TNF- $\alpha$ and GAPDH were 293 and $138 \mathrm{bp}$, respectively (Figure 1).

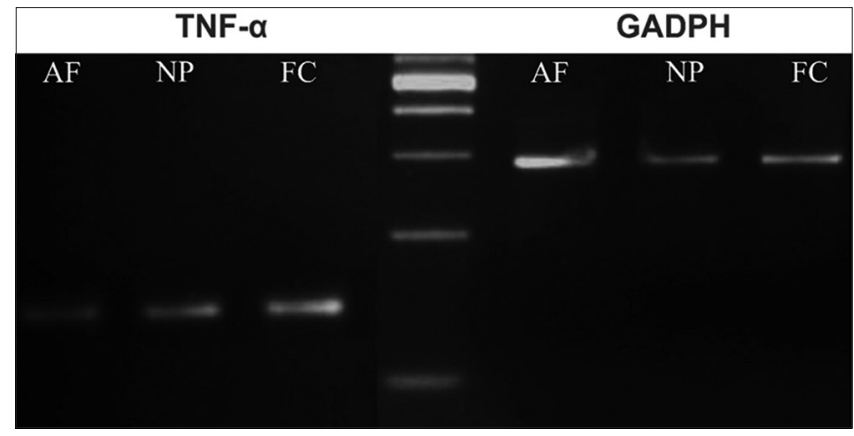

Figure 1: Electrophoresis results of tumor necrosis factor- $\alpha$ expression in experimental sample and control groups (glyceraldehyde 3-phosphate dehydrogenase) in annulus fibrosus (AF), nucleus pulposus (NP) and facet joint (FC)

The highest median of TNF- $\alpha$ expression was at the location of the paraspinal muscle (4.80), followed by TNF- $\alpha$ expression at the annulus fibrosus (2.32), facet joint (0.94), nucleus pulposus (-2.01), and ligamentum flavum (-5.86) (Figure 2).

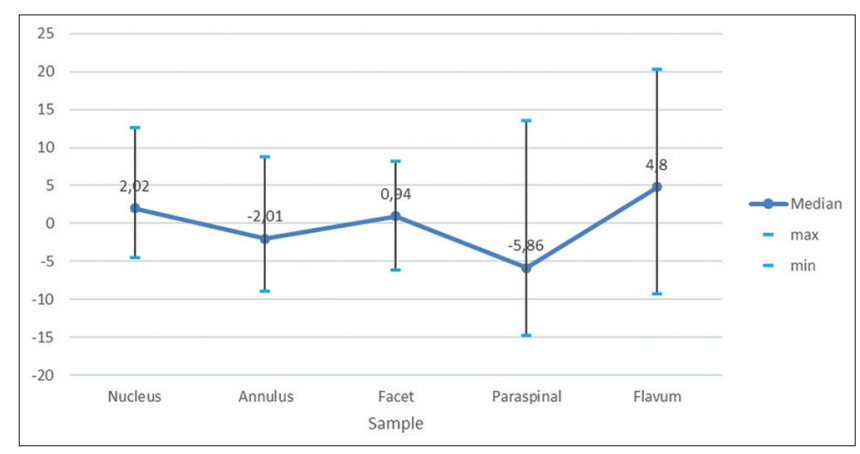

Figure 2: Data distribution of median of tumor necrosis factor-a expression in annulus fibrosus, nucleus pulposus, facet joints, ligamentum flavum, and paraspinal muscle (normalized with glyceraldehyde 3-phosphate dehydrogenase as internal control)

Significant correlation of pain before surgery with the expression of TNF- $\alpha$ was observed in facet joints $(r=0.893, p<0.001)$, meanwhile in other areas: annulus fibrosus, nucleus pulposus, flavum, and paraspinal muscles, the results were insignificant (Table 1). Significant correlation of the clinical condition with TNF- $\alpha$ expression was found in facet joints ( $p<0.001)$, but not in annulus fibrosus, nucleus 
pulposus, flavum ligament, and paraspinal muscles (Table 2).

Table 1: Correlation of pre-operative pain VAS with TNF- $\alpha$ expression in annulus fibrosus, nucleus pulposus, facet joints, ligamentum flavum, and paraspinal muscles

\begin{tabular}{llll}
\hline Parameters & VAS & & \\
\cline { 2 - 4 } & Median & r-value (coefficient correlation) & -value \\
\hline Anulus fibrosus & 2.02 & -0.443 & 0.199 \\
Nucleus pulposus & -2.01 & 0.184 & 0.611 \\
Facet joint & 0.94 & 0.893 & $<0.001$ \\
Flavum ligament & -5.86 & -0.399 & 0.253 \\
Paraspinal muscle & 4.80 & -0.58 & 0.07 \\
\hline TNF- - T
\end{tabular}

Significant association of axial pain before surgery with TNF- $\alpha$ expression was seen in facet joints $(p<0.002)$ but not in other locations of annulus fibrosus, nucleus pulposus, flavum ligament nor paraspinal muscles (Table 3).

Table 2: Correlation of pre-operative condition (ODI) with TNF- $\alpha$ expression in annulus fibrosus, nucleus pulposus, facet joints, ligamentum flavum, and paraspinal muscles

\begin{tabular}{llll}
\hline Parameters & ODI & & \\
\cline { 2 - 4 } & Median & r value (coefficient correlation) & -value \\
\hline Anulus fibrosus & 2.02 & -0.031 & 0.933 \\
Nucleus pulposus & -2.01 & 0.159 & 0.661 \\
Facet joint & 0.94 & 0.948 & $<0.001$ \\
Flavum ligament & -5.86 & -0.476 & 0.164 \\
Paraspinal muscle & 4.80 & -0.526 & 0.118 \\
\hline ODI: Oswestry disability index; TNF-a: Tumor necrosis factor- $\alpha$. &
\end{tabular}

Significant association of radicular pain with TNF $\alpha$ expression was found in facet joints ( $p<0.002$ ). However, there was no significant association found in annulus fibrosus, nucleus pulposus, flavum ligament, nor paraspinal muscles (Table 4). Furthermore, no

Table 3: The association of pre-operative axial pain with TNF- $\alpha$ expression in annulus fibrosus, nucleus pulposus, facet joints, ligamentum flavum, and paraspinal muscles

\begin{tabular}{lll}
\hline Parameters & Axial pain & \\
\cline { 2 - 3 } & Median TNF- $\alpha$ & p-value \\
\hline Anulus fibrosus & 2.02 & 0.422 \\
Nucleus pulposus & -2.01 & 0.909 \\
Facet joint & 0.94 & 0.002 \\
Flavum ligament & -5.86 & 0.326 \\
Paraspinal muscle & 4.80 & 0.137 \\
\hline TNF- $\alpha$ : Tumor necrosis factor- $\alpha$. & &
\end{tabular}

association was found between TNF- $\alpha$ expression and American Spinal Injury Association scores (Table 5).

\section{Discussion}

This study showed significant differences in TNF- $\alpha$ expression across specific spine structures, with the highest expression at paraspinal muscle, followed by annulus fibrosus and facet joint capsule. Previous study reported that inflammatory cytokines are released from lumbar facet joints with osteoarthritic changes in degenerative lumbar spinal disorders [4]. Other study revealed that TNF- $\alpha$ expression in the facet joint was higher compared to the annulus fibrosus and nucleus pulposus. Despite the previous findings, this study comprehensively compared all tissues that may contribute to an inflammatory condition in degenerative spine conditions. Paraspinal muscle, facet joint capsule, ligamentum flavum, annulus fibrosus and nucleus pulposus were sampled in regard to $360^{\circ}$ locations that related to degenerative spine pathology. High inflammatory mediators were found due to the degenerative process in the facet joint and relate to the circumferential pathology of the lumbar spine [5].

Table 4: The association of pre-operative radicular pain with TNF- $\alpha$ expression in annulus fibrosus, nucleus pulposus, facet joints, ligamentum flavum, and paraspinal muscles

\begin{tabular}{lll}
\hline Parameters & Radicular pain & \\
\cline { 2 - 3 } & Median & -value \\
\hline Anulus fibrosus & 2.02 & 0.422 \\
Nucleus pulposus & -2.01 & 0.909 \\
Facet joint & 0.94 & 0.002 \\
Flavum ligament & -5.86 & 0.326 \\
Paraspinal muscle & 4.80 & 0.137 \\
\hline TNF-a: Tumor necrosis factor- $\alpha$. & &
\end{tabular}

TNF- $\alpha$ is a cytokine that can stimulate inflammatory responses, induce nerve swelling and neuropathic pain, promote cellular apoptosis via its cytotoxic effect, and is also the main pain-mediating cytokine [6], [7]. To date, no study has reported the evaluation and comparison of circumferential tissue expression of TNF- $\alpha$ level with regards to degenerative lumbar canal stenosis. Previous studies mostly compared two specific structures of the spine. One of the studies reported that the expression of TNF- $\alpha$ is higher in the annulus fibrosus than nucleus pulposus in patients with lumbar degenerative disease. Meanwhile, another study showed that TNF- $\alpha$ expression, using immunohistochemistry, was higher in the ligamentum flavum compared to the paraspinal muscles [8], [9]. Our study comprehensively explained the connection between all the specific structures in the spine with subsequent correlation of VAS and ODI score.

Table 5: The correlation of pre-operative American Spinal Injury Association (ASIA) scores with TNF- $\alpha$ expression in annulus fibrosus, nucleus pulposus, facet joints, flavum ligament, and paraspinal muscle

\begin{tabular}{llll}
\hline Parameters & Asia & & \\
\cline { 2 - 4 } & Median & r-value (coefficient correlation) & p-value \\
\hline Anulus Fibrosus & 2.02 & -0.241 & 0.318 \\
Nucleus Pulposus & -2.01 & -0.241 & 0.258 \\
Facet joint & 0.94 & -0.143 & 0.329 \\
& -5.86 & & \\
Flavum ligament & 4.80 & & 0.367 \\
Paraspinal muscle & 2.02 & -0.241 & 0.257 \\
\hline TNF-a: Tumor necrosis factor- $\alpha$. & & &
\end{tabular}

Compression of nerve roots due to deformation of the facet joint was reported by Goldwait et al., which is known to be one of the causes of low back pain and sciatica. Facetjoint-associated pain can also be caused by mechanical stress, osteoarthritic changes, inflammation of the joint synovium, or external injury. In recent years, various studies have reported the possibility of cytokines, which are produced from cartilage and synovial tissues, being linked to the advancement of osteoarthritis and generation of pain [10]. In this study, expression of 
TNF- $\alpha$ in the lumbar facet joint was correlated with the level of pain that was evaluated by VAS.

The type of pain found in this study was divided into axial and radicular pain. Axial pain was correlated with the increasing of TNF- $\alpha$ expression in the facet joint. Repeated mechanical stress or trauma and spinal deformity by secondary overload on a degenerated facet joint may be a more important contributor to produce the axial pain in this study. Therefore, it is possible that inflammatory cytokines produced in the facet joint leak into the intraspinal space through the lateral part of the ventral joint capsule tear and affect the lumbar nerve root through an inflammatory process [10].

Previous study found a significant correlation between TNF- $\alpha$ expression in the annulus fibrosus and nucleus pulposus to cause VAS score $(\geq 3.5)$ in patients with lumbar degenerative disease. However, this study did not test other specific structures in the spine. This current study revealed the expressions of TNF- $\alpha$ on the facet joint have a significant correlation with the increase of VAS score. This result indicates that TNF- $\alpha$ in the facet joint cartilage was associated with patients' pain and declining quality of life that were evaluated by ODI functional score. Previous study found that there was a correlation between the expression of TNF- $\alpha$ with the increase of ODI score [11]. The increase expression of TNF- $\alpha$ in the facet joint, allows the clinician to perform the minimally invasive intervention in the facet join to reduce pain, such as performing facet joint blocks or radiofrequency ablation [12], [13], [14].

\section{Conclusion}

TNF- $\alpha$ expression, especially in the facet joint, showed significant association with the pain intensity and pre-operative ODI thus will be the subject for management and procedure in lumbar canal stenosis patients.

\section{Acknowledgment}

This study has been supported by Dana Masyarakat Grant of the Faculty of Medicine, Public Health and Nursing, UGM. We would like to thank our laborant, Fatmawati, for the contribution and great help during the laboratory work and Klinik Bahasa of Faculty of Medicine, Public Health and Nursing, UGM, for the language editing support.

\section{References}

1. Igarashi A, Kikuchi S, Konno S. Correlation between inflammatory cytokines released from the lumbar facet joint tissue and symptoms in degenerative lumbar spinal disorders. J Orthop Sci. 2007;12(2):154. https://doi.org/10.1007/ s00776-006-1105-y

PMid:17393271

2. Moe KT, Khairunnisa K, Yin NO, Chin-Dusting J, Wong P, Wong MC. Tumor necrosis factor $\alpha$-induced nuclear factorkappaB activation in human cardiomyocytes is mediated by NADPH oxidase. J Physiol Biochem. 2014;70(3):769-79. https:// doi.org/10.1007/s13105-014-0345-0

PMid:25059721

3. Johnson ZI, Schoepflin ZR, Choi H, Shapiro IM, Risbud MV. Disc in flames: Roles of TNF- $\alpha$ and IL- $1 \beta$ in intervertebral disc degeneration. Eur Cell Mater. 2015;30:104. https://doi. org/10.22203/ecm.v030a08

PMid:26388614

4. Igarashi A, Kikuchi S, Konno S, Olmarker K. Inflammatory cytokines released from the facet joint tissue in degenerative lumbar spinal disorders. Spine. 2004;29(19):2091-5. https://doi. org/10.1097/01.brs.0000141265.55411.30

PMid: 15454697

5. Whitfield PC, Gherle MS. Treatment options and pathophysiology of degenerative spine disease. Surgery 2018;36(7):362-9. https://doi.org/10.1016/j.mpsur.2018.04.006

6. Khan AN, Jacobsen HE, Khan J, Filippi CG, Levine M, Lehman RA Jr., et al. Inflammatory biomarkers of low back pain and disc degeneration: A review. Ann N Y Acad Sci. 2017;1410(1):68-84. https://doi.org/10.1111/nyas.13551

PMid:29265416

7. Sutovsky J, Benco M, Sutovska M, Kocmalova M, Pappova L, Miklusica J, et al. Cytokine and chemokine profile changes in patients with lower segment lumbar degenerative spondylolisthesis. Int J Surg. 2017;43:163-70. https://doi. org/10.1016/j.jjsu.2017.06.024

PMid:28600230

8. Zhang $\mathrm{Y}, \mathrm{Xu} \mathrm{H}, \mathrm{Hu} \mathrm{X}$, Zhang $\mathrm{C}$, Chu $\mathrm{T}$, Zhou $\mathrm{Y}$, et al. Histopathological changes in supraspinous ligaments, ligamentum flava and paraspinal muscle tissues of patients with ankylosing spondylitis. Int J Rheum Dis. 2016;19(4):420-9. https://doi.org/10.1111/1756-185x.12305

PMid:24597761

9. Zhang C, Chen Z, Meng X, Li M, Zhang L, Huang A. The involvement and possible mechanism of pro-inflammatory tumor necrosis factor alpha (TNF- $\alpha$ ) in thoracic ossification of the ligamentum flavum. PLoS One 2017;12(6):e0178986. https://doi.org/10.1371/journal.pone.0178986 PMid:28575129

10. Boddeke EW. Involvement of chemokines in pain. Eur $J$ Pharmacol. 2001;429(1-3):115-9.

PMid:11698032

11. Tobinick EL, Britschgi-Davoodifar S. Perispinal TNFalpha inhibition for discogenic pain. Swiss Med Wkly. 2003;133(11-12):170-7.

PMid: 12715286

12. Lewandrowski KU. Successful outcome after outpatient transforaminal decompression for lumbar foraminal and lateral recess stenosis: The positive predictive value of diagnostic epidural steroid injection. Clin Neurol Neurosurg. 2018;173:38-45. https://doi.org/10.1016/j. clineuro.2018.07.015 
PMid:30075346

13. Ter Meulen BC, Maas ET, Vyas A, van der Vegt M, de Priester $\mathrm{K}$, de Boer MR, et al. Treatment of acute sciatica with transforaminal epidural corticosteroids and local anesthetic: Design of a randomized controlled trial. BMC Musculoskelet Disord. 2017;18:215. https://doi.org/10.1186/s12891-017-1571-8
PMid:28545491

14. Bartleson JD, Maus TP. Diagnostic and therapeutic spinal interventions: Facet joint interventions. Neurol Clin Pract. 2014;4(4):342-6. https://doi.org/10.1212/ cpj.0000000000000044

PMid:29473559 